\title{
Professional artefacts: evaluating creative outcomes for work-based inquiry
}

\author{
Paula McIver Nottingham \\ Department of Education, Middlesex University, London, UK
}

\begin{abstract}
Purpose - This paper aims to explore graduate perspectives about the creation and use of professional artefacts to communicate work-based inquiry projects to professional audiences.

Design/methodology/approach - The study was based on constructivist qualitative interviews with 14 graduates from a part-time professional practice in arts programme and used thematic analysis to interpret and discuss the findings.

Findings - Participants indicated a perceived value in the use of the professional artefact as a way of articulating their professional inquiry. Professional artefacts enable essential communication skills for professional contexts, have the capacity for engaging with professional audiences that are external to the university, have the potential for enabling further study and workplace employability, show awareness of project management and leadership capabilities and helped some individuals build on and share their own personal philosophy of practice with peer professionals.

Research limitations/implications - As a small-scale research project that used purposive sampling, the findings are not representative, but could provide the creative means to develop professional artefacts within work-related educational programmes and workplace learning programmes.

Practical implications - It is argued that the process and production of professional artefacts can provide the means for communicating work-based projects to professional audiences within workplace settings.

Originality/value - Professional artefacts explore and present developmental aspects of work-based inquiries with distinctive creative approaches to favour practice knowledge and innovation that can be expressively shared with peer professionals.
\end{abstract}

Keywords Professional artefact, Work-based learning, Work-based projects, Inquiry, Communication, Creative arts Paper type Research paper

\section{Introduction}

There is often discussion about the purpose of higher education in terms of preparing individuals for the workplace and the introduction of employability for those studying an undergraduate degree. Learning is about a future job role. In the case of work-based learners, this discussion focuses not on whether job-related studies are being undertaken, but about how university study aligns with and sustains on-going professional practice. In particular, the work-based project is a significant element for the final assessment for work-based studies that addresses the integration of situated workplace learning with academic knowledge (Lester and Costley, 2010; Fergusson et al., 2018). In this paper, the negotiated work-based project, or inquiry, is seen as a "as a 'capstone' project” (Healey and Jenkins, 2009) equivalent to a dissertation but providing a more practical focus. The final-year project is recognised internationally as a significant element of coursework (Healey et al., 2013) and is an important milestone for university students as they complete their degree.

This paper explores the use of professional artefacts within a final work-based project from an undergraduate professional practice in arts programme in the UK. The professional

(C) Paula McIver Nottingham. Published in Journal of Work-Applied Management. Published by Emerald Publishing Limited. This article is published under the Creative Commons Attribution (CC BY 4.0) licence. Anyone may reproduce, distribute, translate and create derivative works of this article (for both commercial and non-commercial purposes), subject to full attribution to the original publication and authors. The full terms of this licence may be seen at http://creativecommons. org/licences/by/4.0/legalcode
Professional artefacts 
JWAM

12,2

artefact represents one coursework element within a 60-credit negotiated work-based project module. Project-based learning is recognised as a way to integrate work-based learning within an authentic workplace context and can include differentiation based on the learner's experience and needs (Cedefop, 2015). In this research, participants who had graduated from the programme (now revalidated in a new faculty) discussed the meaning of the professional artefact using their own viewpoints and experiences. Their responses are then considered as a way to explore the use of professional artefacts within work-based projects and the professional practice curriculum.

\section{Context for professional artefacts within work-based projects (inquiries)}

Work-based research projects, or professional inquiries, have had a long tradition within work-based learning pedagogy (Boud and Costley, 2007) where there is an emphasis on professional learning as a form of lifelong or "human learning" (Jarvis, 2006). This practicebased study centres on undertaking a project in the workplace that focuses academic studies on a real-world problem (Robson, 2002) within a professional context. As a part of a workbased project, the individual learner explores a topic related to their professional role within an organisation, team or community of practice (Lave and Wenger, 1991). The inquiry involves pragmatic insider-research (Costley et al., 2010) as a way of problem-solving or improving practice in a broad professional context that involves creating positionality, reflexivity and impact within the workplace (Wall et al., 2017). Work-based studies have many points in common with progressive higher education pedagogy that embraces more flexible conditions within higher education (Barnett, 2014) and encourages a wider understanding of graduate attributes like learner empowerment, transformative capabilities, crossing boundaries and social learning (Ryan and Tilbury, 2013).

Work-based projects can be adapted for emerging and establishing practitioners as well as experienced senior managers, allowing individuals to explore a topic within their workplace context critically and reflectively while sharing practice and findings with workplace teams as a part of organisational learning (Critten, 2016). The goal of a work-based project is to establish a personal perspective and independent learning capabilities as well as professional competences (Bravenboer and Lester, 2016). There is the freedom to choose a negotiated topic that is most relevant within a work or subject discipline, identifying situated knowledge and aligning this knowledge within the wider professional context of policy and practice. Peer review and the use of critical friends within the workplace are encouraged. There is a sense that while students are already employed, the work-based project can enhance greater "employability" initially defined by Yorke as: "a set of achievements - skills, understandings and personal attributes - that makes graduates more likely to gain employment and be successful in their chosen occupations, which benefits themselves, the workforce, the community and the economy" (2006, p. 8). It is recognised that the policy and practice of employability has some contested aspects (Reid, 2016); however, generally, the attributes expected within occupations are a consideration for higher education (Rees et al., 2007). Fleming and Haigh (2017), when studying work-integrated learning, point to more recent definitions of employability that focus on "ability" (citing Bennett, 2016) and the importance of developing attributes and capabilities that are dynamic and futurefacing. Walsh and Powell (2018) discuss how some work-based learners develop a perspective consistent with an "intrapreneurship" approach that enables them to problematise and more deeply engage with their own work context.

In the context of this research using an arts-based example, the professional artefact is designed to explain the professional inquiry process, including literature, methodology, findings, analysis and conclusions/reflections that come from undertaking the work-based project (inquiry) in a form that is meaningful and recognisable to other creative professionals in a professional context (the audience). The professional artefact also includes outcomes (workshops, events, products, services) from activities that were generated during the project. 
It is an integral part of the inquiry-based learning represented by the project work undertaken, but also associates the student with their disciplinary research community (Healey and Jenkins, 2009) as well as their professional community. This study follows on from earlier research that acknowledged the need for an embodied process that supports the use of professional inquiry in the arts (Nottingham and Akinleye, 2014). There is also the need to develop creative practice beyond the arts discipline, and the findings from this research include a workplace practice that supports multi-disciplinary professional artefacts.

As the programme of study had a range of arts professionals, there was an emphasis on providing some generic work-based learning guidance, as well as the creative means to investigate the arts disciplines and creative employment sector in more depth. The explanation for the professional artefact element was given in the module handbook, with examples shown in group workshops. The guidance indicated that the purpose of the professional artefact was to creatively frame the work-based inquiry for a professional audience, including evidence of the research and activities. The professional artefact could be created in various formats such as a booklet or poster or an artefact created in film or audiovisual designed to communicate to an audience at a distance. Instructions for this piece of work included the use of language that is meaningful to other professionals, possibly using new technologies and social media. A critical one-page explanation of the artefact could be stated in a first person narrative. The guidance indicated that the professional artefact should show an awareness of what is going on in the work-based student's field of practice in terms of theories and discourses and demonstrate an understanding of indicative bodies of knowledge when communicating the inquiry/artefact. It was also important that the inquiry/ artefact demonstrates personal understanding of learning and insights about practice that might benefit or have implications for a particular professional community. The inquiry was presented as a way to allow for practitioners who did not intend to become academic researchers to carry out work-based inquiries and encourage independent self-managed learning. As in any capstone project, individuals were expected to review literature and investigate policy within a particular sector, so the inquiry actions/activities would have direct relevance to the situation or issues being investigated.

\section{Professional inquiry literature: creative approaches to guide the professional practice inquiry}

Within the work-based inquiry and as a way of considering the professional artefact, practice-based and theoretical sources were given as samples to study and learn from rather than presenting mandates for disciplinary or sector considerations. Students and staff were encouraged to explore and find new sources using interdisciplinary multidisciplinary and transdisciplinary approaches to engaging with knowledge. Sources from the arts and creative industries were introduced as ways of thinking about experience and theorising practice, but sources were also sought to explain existing theories in use from the workplace that could be examined as principles for practice. Many arts-related thought leaders have given guidance to developing professional practice in the arts as well as research directions to guide those doing research in this area. It would be noted that the arts, both performance and visual arts, has a long history of practice-based research, where the productions are shown in their original forms to communicate, for example, a performance or a photograph.

This way of working is related to the principles of pragmatism (e.g. Dewey, 1910). The methodology of the "professional inquiry" is a pragmatic approach that allows work-based students to emerge from their learning experience with a learner-centred perspective as well as an academic and professional skillset that addresses the need to communicate project findings to various professional audiences. The combination of the artefact and the thinking
Professional artefacts 
JWAM

12,2

and doing that was required to create it are not seen as separate within the process. Dewey speaks about the act of expression and the expressive object as "fusion": "The expressiveness of the object is the report and celebration of the complete fusion of what we undergo and what our activity of attentive perception brings into what we receive by means of the senses" (Dewey, 1934, p. 107).

Gardner introduced the theory of multiple intelligences in the early 1980s (2004) that describes human cognitive competence as a set of abilities, talents or mental skills, categorised as intelligences such as language, music, visual-spatial and bodily kinaesthetic; this way of thinking recognised and reflected a wider appreciation of human intelligence and behaviour (Gardner, 2006). These intelligences do not stop within education, but are important consideration for the workplace and could inform how we view intelligence within various occupational roles; as such they could provide a wider profile for individuals as a way of understanding the interplay of intelligences in the workplace (Gardner and Moran, 2004).

Smith and Dean (2009) speak about the iterative creative research cycle as a web-like structure of idea generation, which the authors state can actively be pursued in both the humanities and the sciences. The model follows a circle of development that encompasses academic practice-led research and research-led practice. Smith and Dean's way of generating ideas can be used for both creative practice and research where a process-driven and goaloriented way of working speaks to the importance of evaluation (so working to project briefs); peer review and promotion within creative project work and the measure of impact in economic and social-cultural terms are also seen as part of research planning. Similarly, Dallow suggests that research in the creative arts can be seen as: research into arts practice, research through arts practice and research for arts practice (Dallow, 2003). Jackson (2011) makes it clear that engagement or emersion in an experience (e.g. life-wide) is an intentional act, and one that is important to pursue.

Leavy (2011) introduces the use of transdisciplinary approaches for problem or issuecentred arts projects, such as in arts-based community collaborations. Researching into complex issues in the real-world practice crosses disciplinary boundaries and brings the need for new conceptualising frameworks and strategies for evaluation. "Transdisciplinary research practices are issue- or problem-centred approaches to research that prioritize the problem at the center of research over discipline-specific concerns, theories or methods" (Leavy, 2011, p. 14). Prioritising the "problem" in this way focuses the questions that trigger research/inquiry and are helpful when considering the professional inquiry/artefact as new practice where innovation is present, but based on providing solutions within an individual's practice or workplace organisation.

As the professional artefact could, in fact, be a physical act, such as a theatre or dance performance, this way of thinking can be a part of how students in the arts might perceive of sharing their inquiry with peer professionals. Twyla Tharp (2007) was introduced by the programme's specialist dance professional and led to a powerful way to think about dance and performance practice within the artefact. "I will keep stressing the point about creativity being augmented by routine and habit. . It is the perennial debate, born in the Romantic era, between the beliefs that all creative acts are born of (a) some transcendent, inexplicable Dionysian act of inspiration, a kiss from God on your brow that allows you to give the world The Magic Flute, or (b) hard work" (Tharp, 2007, p. 7).

Creative thought leaders, like Csikszentmihalyi (1996), have written about how to achieve original and innovative work, speaking about creative domains as symbolic knowledge fields where individuals can act as gatekeepers or act to compliment creative systems in use through new ideas or patterns that they add to the domain. The "flow experience" is one of enjoyment, with clear goals and immediate feedback to balance challenges and fear of failure (Csikszentmihalyi, 1996). 
Ken Robinson (2017) has spoken about creativity in education and creative innovation in business practice. In his book chapter "Being a Creative Leader", Robinson suggests cultivating three main processes (1) imagination as the ability to bring to mind events and ideas not present to our senses, (2) creativity as original ideas that have value and (3) imagination as "putting original ideas into practice" (2017, p. 187). As a practitioner, Robinson's notions of actively embedding creative practice in our everyday lives provide a way to introduce collaboration and engagement within the context of the organisation and workplace.

Not all creative thinkers celebrate what they consider to be specialist art-related creative approaches. De Bono (1971) differentiates his lateral thinking as "inventions" as opposed to artistic creativity; to him "Creative thinking often requires a talent for expression, whereas lateral thinking is open to everyone who is interested in new ideas" (1971, p. 14). De Bono presents thinking that gets away from dominant ideas by utilising play and the use of chance. Perhaps, in the digital age, using computer-assisted technology will allow more professionals to play as well as think creatively.

\section{Research approach: gathering graduate points of view}

To explore the actual use of professional artefacts within arts-based inquiries, research was undertaken with graduates who had studied professional practice as a part of a larger research initiative. Fourteen graduates from a range of seven cohorts on one undergraduate programme were purposively chosen to be interviewed about the artefacts that they had completed as a part of their work-based project module. The final sample included 12 females and two males. Some of the participants had completed their studies up to four years prior to the interview, while others were recent graduates. The research sought to find out how the artefacts were perceived as a part of a final-year professional inquiry and after graduation, in terms of how the artefact might have contributed to professional workplace roles or further studies.

Participants (designated by the anonymised letters A-N) included practitioners from a variety of arts practices, including several musical theatre performers, a graphic designer, a theatre/community volunteer, a theatre performer/arts manager, a graphic designer/teacher, a performer working in a school, a company dancer, several dance business owners/teachers, a freelance dancer in transition and a theatre performer in transition. On entering the programme, the graduates had varied levels of experience; some of the students were establishing their careers in the arts after initial training from a sub-degree or professional body arts qualification, while others had established practices with over five years of experience in the workplace before starting the degree. All of the graduates completed the undergraduate degree in good standing.

The participants were interviewed using the interpretivist qualitative methodology (Mason, 2018) by the author/researcher who has had formal social science research training. The interviews generally lasted around $30 \mathrm{~min}$ to $1 \mathrm{~h}$ in person or via Skype and were taped (audio) and transcribed for accuracy. The data were interpreted using thematic analysis, interpretive reading and analytic induction (Ritchie et al., 2014; Mason, 2018; Bryman and Bell, 2015) to code the interviews and establish themes. The physical presence of the professional artefacts from the 14 participants varied; some took the form of films, performances and demonstrations, many were in digital form, some were originally displayed online within public websites or blogs and some of the actual artefacts were only shared within workplace settings. Ethical permissions from the university were given prior to contacting the graduates, and informed consent forms were used during the research process. Invitations to participate were sent via email, and these were followed up by sending information sheets and interview questions to the participants.
Professional artefacts 
JWAM

12,2

132

\section{Participant questions included}

(1) What was the main focus or meaning of your final inquiry?

(2) What was the main focus or meaning of your professional artefact?

(3) What was the role of the artefact within your workplace/community of practice?

(4) How has the professional artefact informed or made a difference to your current work outcomes that you work with now?

There were a number of limitations to the research. The volunteer participants were chosen purposively based on the evidence of coursework produced during their studies. All of the participants had the same tutor/advisor, so this may have limited the responses. However, this also meant that the qualitative interviews/discussions could be more probing because of the familiarity with the coursework and workplace context. Finally, graduates were more comfortable with an anonymised study, limiting the written, visual and audio-visual evidence that could be identified within the paper, so for ethical reasons, the intended content analysis of the professional artefacts was not done.

\section{Graduate points of view: interview findings and discussion}

The research findings indicate a number of themes about the professional artefact. Overall, participants indicated a perceived value in the use of the professional artefact as a way of articulating their professional inquiry. Professional artefacts enable essential communication skills for professional contexts. Artefacts have the capacity for engaging with professional audiences that are external to the university and have the potential for enabling further study and workplace employability. The participants demonstrated an awareness of project management and leadership capabilities, and the process helped some individuals build on and share their own personal philosophy of practice with peer professionals. The explanations of the research findings are explored in six main themes.

Theme 1: Participants indicated a perceived value in the use of the professional artefact as a way of articulating the professional inquiry. They discussed the process of developing the professional artefact and how this process led to a more holistic sense of discovery using professional practice knowledge. While the professional inquiry/artefact started out as a piece of university coursework, it became more of an integral way to consider practice.

The artefact, as planned, told the same story as the inquiry but in a different way to a different audience, so could embody the thinking and the practice in a different way:

So, what I'm saying is it's the thinking that is the artefact, it's the processes behind the practice that's of equal value rather than this end, you know, three tips for doing a good workshop... I think it's the approach to the practice that the kids thought 'this is different' and this is coming from something they're not getting [in school] which is the approach to the thinking behind the practice (Participant E).

The artefact became a way to express individual points of view and nuanced insights:

Uh, let's see if I can remember. . I think I used a thing called meme, which is the tacit knowledge, the thing, also things that transmit. . .one of the difficult things about sports and music and dance is... learning other people's experience and sensation through tacit knowledge. . . (Participant H).

Critical reflection was an important way to engage with experience:

It was so nice when we had this "circle model" with the working cycle, because I realised that it was the same cycle like with creativity, just with different words, and I was like "I could actually try to do this, this way" (Participant A). 
Theme 2: Professional artefacts enable essential communication skills for professional contexts, telling a story, choosing an audience, using disciplinary and sector specific language.

The professional artefact was seen as a way to speak to and benefit other students and peer professionals:

I wanted to have. . .other graphic designers so that they can use directly, in their work. . .and to specify the target pool, on the one hand, and to use visual elements, for this specific target group. So, it should be help for other graphic designers (Participant C).

I mentioned to somebody and quite a few of my colleagues then watched it which I think was really nice for them as well, um, to see some of the research and look at it and that was really nice. They left some nice comments and things, so that was nice for my colleagues to see it as well (Participant L).

I remember at the time, I'd just started to kind of, watch more of those kind of YouTube videos where people do vlog, which kind of inspired me to do it, because I mean there's people that vlog about all sorts of stuff. ... (Participant B).

The first artefact which was sort of a collection, a literary collection of plays and playwrights. . . in my [PGCE] training. . . I rebuilt it up again, added to it, and shared it amongst people on the course and it was a really impressive artefact, it, sort of, went through the course again and I used it again. . . and it's been a really useful tool. .. I then also felt that I wanted to create a video, a YouTube video, which was a sort of informal, accessible instruction of how to go from being an artist to becoming a teacher... it's just my practice, my practice, it's all from one thought. It's all based in my principles of integrity, truth and telling a story and it's taken me a long time to get there... (Participant E).

One professional artefact contained evidence of a dance workshop with a musical theatre production crew that was filmed and shared backstage:

My artefact was a film... [a] kind of film/documentary. So, I participated in activities... work experience, sort of thing, with all the different departments and they allowed me to film that, and then I ended up teaching, well I invited the ______ _ _ _ _ _ _ _ class. It was my way of giving back... so they got to see themselves as part of something.... it brought everyone together. . . . and it just gave people a little boost on that particular day, so I think it's worthwhile (Participant J).

\section{Many of the artefacts required new ways of working}

So, for my artefact I wrote an article. . I I would imagine seeing in —_ [a trade journal]. . .I kind of actually found it quite, quite challenging and I had to do a bit of research into it and kind of think about how to structure it and how to present it. . . (Participant M).

New technologies make the professional artefacts valuable learning tools for students who can re-purpose the artefact for other projects or professional contexts:

Yes, I think the reason for the filming as with most films is to capture moments that are. . lost once things are said, once discussions are had, once meetings are had, the words are lost forever, the emotions are lost. And I love to capture people's emotions, certainly dancers and physicality. I realised how much I. . . love seeing a body move and making shapes. . . but the filming was to show the difference between the - [genre] dances and how differently they're taught. That's strictly to show... to share with other dancers or amateurs/professionals what is current (Participant $\mathrm{N}$ ).

There was a realisation that as a work-in-progress, the artefact could change in content, for future work or when used as a learning/teaching tool:

I want to be able to make it dynamic, I want to exchange content or extend content if I feel that it's necessary and I cannot do that if it is in a hard copy - it has to be dynamic like websites or articles and
Professional artefacts 
JWAM

12,2

this is a completely different format. . . I don't want it to be a time capsule. . . I'm not sure how yet so the artefact for the programme was its own thing. . Students found it useful at the time but it needs to be updated (Participant A).

Theme 3: The artefact has the potential for engaging with professional audiences that are external to the university, relating to a transdisciplinary approach to workplace problemcentred issues. As Walsh and Powell indicate, professional studies students are employees who undertake research in a context that is familiar to them (2018), and this allows them to use their disciplinary knowledge as well as their knowledge of their immediate workplace.

The professional audience was a factor in the artefact and its production, getting away from the idea that academic-style research should only have an academic audience:

It's the coffee table book version of the write up of the research, isn't it? (Participant E)

Some had to communicate to interdisciplinary or multidisciplinary professional audiences using "new" sector vocabulary to align their messages:

The audience for my artefact, I decided to do it to teachers. . . because it had a lot to do with education. I was a lot different than others on the course because I was actually in a school at the time and I know a lot of people had different audiences, but I think the course taught me that you can use different media and [be] very visual. . . I used to watch lots and lots of videos, Ken Robinson. . . I wanted to do something that would summarise my work but in a visual way and putting that up as a video made much more sense... (Participant L).

Theme 4: The professional artefact process has the potential for enabling further study and workplace employability by creating actual examples and evidence of practice to show business and entrepreneurial capability or potential skillsets to future employers:

So, the actual professional artefact was the website, which was I suppose advertising myself as a business, which would be providing adults, within the corporate world, with workshops... and all different kind of things which were very arts based that could help within their business (Participant D).

The artefact is seen as a useful way of integrating professional practice and university studies based in the workplace, prompting investments in new skillsets that can be used for current and future employment:

... So, it was a website format, consciously chosen, it was a fictional theatre website, because of my topic. . . a website offering me the option to use different types of media as well. . . I had animations on there. I used my own photography, I used my own artwork, I shot a trailer with my friend. . . I edited it myself, added music, yeah, I did the interviews, anonymised them with some of my interview participants... I've got it on my CV, I am proud of it. . (Participant G).

Theme 5: Engaging with a professional audience to develop the inquiry/artefact could show awareness of project management and leadership capabilities.

An inquiry about the therapeutic qualities of art practice that could not ethically show the artwork of others, showed one participant's own perceptions of being an artist:

I remember collating lines of poetry from that year that I studied and then it turned into an abstract script, and then I made it with this [international] filmmaker who helped me use a camera (laughs) and his studio because I had no idea what I was doing. . . and I edited that whole thing. All that stuff. . . I learnt how to edit during that as well. ...I think that's what I found really interesting though, when you contextualise whatever you're trying to portray in as many different ways as you can. . .I guess that's the meaning of visual language isn't it? (Participant F).

... so, the monologue was audio recorded and played on top of the film ....so I wanted to. . .I didn't want it to be just kind of me, like I didn't want it to just be about me. I wanted it to, [as] a reflection of the whole enquiry incorporating like the different voices that were used... like obviously the 
interviews, and the survey... I had so many other people's opinions that I wanted to represent them truthfully and give a well-rounded. ... summary of what I found out (Participant I).

Theme 6: Doing the professional artefact helped some individuals build on and share their own personal philosophy of practice with peer professionals. This related to doing qualitative research, documentaries and the use of critical reflection.

Some were able to use the inquiry/artefact to think about their professional role and how their perceptions of that role were questioned or changed:

Because certain traditions are perhaps outdated now, and perhaps not so much relatable to the current audience that's watching now, especially the young generation. So, we need to ask ourselves questions. . . if we want ballet to live on, what is it that we need to push forward and what is it that we need... to perhaps let go of?... I still, it's really very interesting [be]cause it really, it really shaped the way that I think about dance (Participant K).

So, creating a safe space to allow us to have ... [exposure]. . . there was one piece of literature that I looked at and he [the author] was talking about the teacher/student relationship in dance but obviously that could be carried out to performing arts, and just how, if that is affected, the knock on effect of that is quite scary. It really affects how one expresses themselves through their art form and how, yeah, it can really negatively impact how we create, and how it kind of restrains us and chains us (Participant I).

So, when I'm teaching, I always try to make student relax fast, because that's what Csikszentmihalyi said, you need to relax and also you need to enjoy what you're doing, rather than being told to focus or being shouted at. . (Participant $\mathrm{H}$ ).

I mean I have to say I, the course, it changed the way I thought and it changed the way I wrote, specifically, even though I was reflecting on my creative practice, it did change the way I think and the way I wrote (Participant E).

\section{Relevance of graduate views about creative professional artefacts}

The findings provide a particular insight about the longevity and relevance of the professional artefact as a part of university study and as a way of communicating research findings as artefacts to peer professionals in the workplace. The discussions with graduate participants define some of the benefits and challenges for those undertaking professional practice/work-based studies. The purpose of professional artefacts is to actively seek to engender learning empowerment and crossing boundaries (Ryan and Tilbury, 2013) and can put the practitioner in charge of negotiating their engagement in the final capstone project (Healey and Jenkins, 2009). The proviso of introducing the professional artefact is that it is dependent on the circumstances of a live work-based project, so can be quite dependent on the context in which the project is taking place.

Personalising and professionalising practice through inquiry and demonstrating that knowledge is key to presenting the professional artefact. The ability to achieve employability goals relates to the notion of "self-belief" linked to the conviction in one's ability to achieve one's own goals and such a notion includes consideration of the environment or context in which that ability is enacted (Turner, 2014). Critical reflection is used to establish this within a creative design process as well as with the presentation of the artefact itself. The "circle model" (Participant A) has tangible outcomes that can be shared in terms of products, processes and services. As Helyer points out: "Ideally reflective practitioners will harness and combine the intellectual and the emotional with their operational practices. Rather than a onedimensional response this catalyst will produce an ongoing process where thinking, acting, questioning and collaborating are brought together in a supportive combination, creating nuanced, smart responses and superior results" (2015, p. 17).
Professional artefacts 
JWAM

12,2

\section{Leveraging professional artefacts for greater application}

Within the process of the professional artefact, application within the professional inquiry (project) is seen as essential. As a robust "capstone project" variant to the dissertation, insights from graduates who were using the knowledge gained from the work-based inquiry/ professional artefact was useful. Artefacts involved the creative arts sector and other occupational areas in which they were working, requiring entrepreneurship, project management and leadership thinking that went beyond what had been expected when the artefact was first introduced as coursework. Wenger et al. (2011) show how "value creation" could be measured using stories and interaction combined with indicators to look at the "integrated picture of the value created by a community or network" (2011, pp. 37-38). The professional artefact allowed students to increase "value creation" as their individual interaction and communication with peer professionals amplified through their experience of sharing the artefact.

The framing of the artefact within the professional setting created lasting impressions for the graduates interviewed which have the potential for sharing "practice knowledge" (Siebert and Walsh, 2013) with future work audiences. "The aesthetic understanding of working practices sheds light on the sensory aspects of knowledge, and gives prominence to the hidden and tacit knowledge whereby practitioners are people who 'dwell' in a practice. On becoming a practitioner, learning is constitutive of organizing, just as organizing is constitutive of learning. . knowledge is embodied in their bodies and embedded in the materiality of the artifacts of a practice" (Gherardi and Strati, 2012, p. x).

The ability to manage a work-based project and then to communicate the inquiry to a professional audience required students to think differently about how to collaborate with peer professionals in the conceiving of the artefact, in its production and in its performance/ display. Additional organisational management skills might include negotiation, strategy development and leadership. Yip et al. (2008) describe a system of work that introduces dialogue, planning and implementing change initiatives as a form of "boundary spanning leadership" to achieve higher collective outcomes. This boundary-spanning behaviour was evident in the graduate interviews as a vital way of negotiating creative practice.

Dewey's (1934) notion of the fusion between the act of expression and the expressive object gives a rationale for presenting professional artefacts to peers as works-in-progress that deliver change while still in a state of change. The application of professional artefacts has the potential to express inquiry findings beyond a transactional mode to incorporate transformative learning (Mezirow, 1991) through the use of critical reflection (Helyer, 2015). As a work-in-progress, the professional artefact, and the elements that make up the artefact, communicate a message that can speak to multiple "intelligences" (Gardner, 2004) within a multidisciplinary professional audience. In the Education 4.0 and Industry 4.0 digital age, the capacity to create a multimodal artefact that can respond to a greater range of professionals is increasingly becoming an expectation of the workplace, such as filmed performances and voiceover PowerPoint presentations. The challenge will be to present knowledge and information to professional peers who articulate experience and outcomes as practice (Smith and Dean, 2009; Dallow, 2003).

\section{Conclusions and further directions}

In conclusion, the findings provide particular insight into the use of the creative professional artefact as a part of the work-based project curriculum. The significance of the artefact as a "dynamic" (Participant A) element in a "capstone project" (Healey et al., 2013) is its ability to translate the more academic outcomes of the inquiry to a relevant creative professional audience. Evaluating the efficacy of the work-based inquiry and communicating its outcomes both play a part in its implications or impact, and these are typically considerations for 
assessing the success of the project. This type of self-efficacy has been linked to realising selfbelief for employability (Turner, 2014). Critical conceptualising of practice and adding a way of utilising key creative thinkers in the inquiry preparation creates a setting for critical reflection and reflexivity that questions practice but also seeks solutions to problem-centred issues (Leavy, 2011).

Professional artefacts are both embodied and evidenced to connect with a relevant professional audience and actively endorse learning empowerment (Ryan and Tilbury, 2013). They put the student in charge of choosing and negotiating the engagement with peer professionals in their final capstone project. The findings indicate transformative learning is a possible outcome (Mezirow, 1991) for students enabling flexible practice by crossing boundaries (Ryan and Tilbury, 2013) and boundary-spanning between university studies and the work context. The framing of the artefact within the professional setting clearly created lasting impressions for the graduates interviewed.

Further research could explore the perspectives and processes that align this type of flexible university study with the growing use of organisational facilitation or coaching as a way of developing staff within particular pathways. Looking at professional artefacts as works-in-progress rather that finalised products liberates the learner to address short- and medium-term goals more readily. In future practice, new technologies make the professional artefacts more portable for students and professionals who can re-purpose the artefact for other projects or professional contexts. We now live in a digital mobile world, and the world of work requires higher education that supports this innovation (Robinson, 2017).

\section{References}

Barnett, R. (2014), Conditions of Flexibility Securing a More Responsive Higher Education System, The Higher Education Academy, New York.

Boud, D. and Costley, C. (2007), "From project supervision to advising: new conceptions of the practice", Innovations in Education and Teaching International, Vol. 44 No. 2, pp. 119-130.

Bravenboer, D. and Lester, S. (2016), "Towards an integrated approach to the recognition of professional competence and academic learning", Education + Training, Vol. 58 No. 4, pp. 409-421.

Bryman, A. and Bell, E. (2015), Business Research Methods, 4th ed., Oxford University Press, Oxford.

Costley, C., Elliott, G. and Gibbs, P. (2010), Doing Work Based Research: Approaches to Enquiry for Insider-Researchers, Sage Publication, London.

Cedefop (2015), Work-based Learning in Continuing Vocational Education and Training: Policies and Practices in Europe, Publications Office of the European Union, Cedefop research paper; No 49, Luxembourg.

Critten, P. (2016), "A radical agenda for enabling organisation transformation through work-applied learning”, Journal of Work-Applied Management, Vol. 8 No. 1, pp. 65-78.

Csikszentmihalyi, M. (1996), Creativity: Flow and the Psychology of Discovery and Invention (Pbk), Harper Collins Publishers, New York NY.

Dallow, P. (2003), "Representing creativeness: practice based approaches to research in creative arts", Art, Design and Communication in Higher Education, Vol. 2 Nos 1-2, pp. 49-66.

De Bono, E. (1971), The Use of Lateral Thinking, Penguin Books, Harmondsworth.

Dewey, J. (1910), How We Think, D. C Heath and Co Publishers, Chicago.

Dewey, J. (1934), Art as Experience, Perigree Trade paperback edition/August 2005, The Berkeley Publishing Company Penguin Group, New York.

Fergusson, L., Allred, T. and Dux, T. (2018), "Work-based learning and research for mid-career professionals: professional studies in Australia", Interdisciplinary Journal of E-Skills and Lifelong Learning, Vol. 14, pp. 1-17.
Professional artefacts 
JWAM

12,2

138

Fleming, J. and Haigh, N.J. (2017), "Examining and challenging the intentions of work-integrated learning", Higher Education, Skills and Work-based Learning, Vol. 7 No. 2, pp. 198-210.

Gardner, H.E. (2004), Multiple Intelligences: New Horizons, 2nd ed., Basic Books, New York, NY.

Gardner, H. (2006), "The development and education of the mind", Abingdon: Routledge. Chapter 12 Artistic intelligences pp. 97-102, Originally in Art Education, National Art Education Association, 1983, Vol. 36 No. 2, pp. 47-49.

Gardner, H.E. and Moran, S. (2004). "At the workplace”, in Gardner, H.E. (Ed.), Multiple Intelligences: New Horizons, 2nd ed., Basic Books, New York, NY.

Gherardi, S. and Strati, A. (2012), "Introduction" in Learning and Knowing in Practice-Based Studies, Edward Elgar Publishing Limited, Cheltenham.

Healey, M. and Jenkins, A. (2009), Developing Undergraduate Research and Inquiry, Higher Education Academy, New York.

Healey, M., Lannin, L., Stibbe, A. and Derounian, J. (2013), Developing and Enhancing Undergraduate Final-Year Projects and Dissertations, Higher Education Academy, New York.

Helyer, R. (2015), "Learning through reflection: the critical role of reflection in work-based learning (WBL)", Journal of Work-Applied Management, Vol. 7 No. 1, pp. 15-27.

Jackson, N. (2011), "An imaginative lifewide curriculum" in Jackson, N. (Ed.), Learning for a Complex World, AuthorHouse, Bloomington, pp. 101-121.

Jarvis, P. (2006), Towards a Comprehensive Theory of Human Learning, Routledge, London.

Lave, J. and Wenger, E. (1991), Situated Learning Legitimate Peripheral Participation, Cambridge Press, Cambridge.

Leavy, P. (2011), Essentials of Transdisciplinary Research (Qualitative Essentials) (Pbk), Left Coast Press, Walnut Creek.

Lester, S. and Costley, C. (2010), "Work-based learning at higher education level: value, practice and critique", Studies in Higher Education, Vol. 35 No. 5, pp. 561-575.

Mason, J. (2018), Qualitative Researching, 3rd ed., Sage Publication, London.

Mezirow, J. (1991), Transformative Dimensions of Adult Learning, Jossey-Bass Publishers, San Francisco.

Nottingham, P. and Akinleye, A. (2014), "Professional artefacts: embodying ideas in work-based learning", Higher Education, Skills and Work-Based Learning, Vol. 4 No. 1, pp. 98-108.

Reid, J. (2016), "Redefining 'Employability' as something to be achieved", Higher Education, Skills and Work-based Learning, Vol. 6 No. 1, pp. 55-68.

Rees, C., Forbes, P. and Kubler, B. (2007), Student Employability Profiles A Guide for Higher Education Practitioners, 2nd ed., The Higher Education Academy, New York.

Ritchie, J., Lewis, J., Nicholls, A.M. and Ormston, R. (2014), Qualitative Research Practice Qualitative Research Practice: A Guide for Social Science Students and Researchers, Sage Publications, London.

Robinson, K. (2017), Out of Our Minds, 3rd ed., John Wiley and Sons, London.

Robson, C. (2002), Real World Research, Second ed., Blackwell Publishing, Oxford.

Ryan, A. and Tilbury, D. (2013), Flexible Pedagogies: New Pedagogical Ideas, The Higher Education Academy, New York.

Siebert, S. and Walsh, A. (2013), "Reflection in work-based learning: self-regulation or self-liberation?", Teaching in Higher Education, Vol. 18 No. 2, pp. 167-178.

Smith, H. and Dean, R.T. (2009), Practice-led Research, Research-Led Practice in the Creative Arts, Edinburgh University Press, Edinburgh.

Tharp, T. (2007), The Creative Habit: Learn it and Use it for Life, Simon and Schuster, New York, NY. 
Turner, N.K. (2014), "Development of self-belief for employability in higher education: ability, efficacy and control in context", Teaching in Higher Education, Vol. 19 No. 6, pp. 592-602.

Wall, T., Bellamy, L., Evans, V. and Hopkins, S. (2017), "Revisiting impact in the context of workplace research: a review and possible directions", Journal of Work-Applied Management, Vol. 9 No. 2, pp. 95-109.

Walsh, A. and Powell, P. (2018), "Supporting student innovation through an engagement, employability and employment ecosystem", Higher Education, Skills and Work-Based Learning, Vol. 8 No. 1, pp. 15-28.

Wenger, E., Trayner, B. and de Laat, M. (2011), "Promoting and assessing value creation in communities and networks: a conceptual framework", Rapport 18, Ruud de Moor Centrum, Open University of the Netherlands.

Yip, J., Wong, S. and Ernst, C. (2008), "The nexus effect when leaders span group boundaries", Leadership in Action, Vol. 28 No. 4, pp. 13-17.

Yorke, M. (2006), Employability in Higher Education: What it is - what it is Not', Learning and Employability Series One, Enhancing Student Employability Co-ordination Team and Higher Education Academy, New York.

\section{Corresponding author}

Paula McIver Nottingham can be contacted at: P.Nottingham@mdx.ac.uk
Professional artefacts

For instructions on how to order reprints of this article, please visit our website:

www.emeraldgrouppublishing.com/licensing/reprints.htm

Or contact us for further details: permissions@emeraldinsight.com 